\title{
Uma cidade que fala. Vozes urbanas nas Silvas de Estácio
}

\author{
Ana Maria Lóio \\ Universidade de Lisboa \\ Centro de Estudos Clássicos
}

O percurso biográfico e poético de Estácio liga-o indelevelmente a duas cidades: Nápoles, onde nasceu e viveu até à adolescência e para onde deseja regressar em idade avançada; e Roma, para onde a família se mudou durante o principado de Nero, e talvez com o apoio deste. É esta última a que goza de maior protagonismo nas Silvas, dada a relação estreita entre a celebração do imperador e a da sua cidade.

Tal celebração assume contornos notavelmente originais. Um dos aspectos que Estácio explora no sentido de tornar o panegírico menos árido é a voz que o profere. Figuras mitológicas que habitam locais simbólicos da Roma de Domiciano adquirem voz nas Silvas para fazer, na primeira pessoa, o elogio do imperador. Gostaria de salientar a peculiaridade de duas dessas (muitas) vozes, que poderão ter-se inspirado em oradores invulgares que elogiam os Ptolemeus na poesia helenística. A extraordinária imaginação do poeta terá transformado o estímulo helenístico num Cúrcio regressado à superfície para louvar Domiciano e num Jano honrado por dividir com o imperador o protagonismo que the cabe no primeiro dia do ano.

\section{O regaço de Parténope}

A Nápoles em que Estácio cresceu era a principal cidade grega da Campânia e o maior centro cultural grego no ocidente. Contrariando o acentuado declínio cultural de outras colónias gregas da Magna Grécia, a colónia da Eubeia, tornada municipium em 90 a. C., manteve uma constituição grega, órgãos de governo locais, instituições cívicas e religiosas e um sistema de educação característicos ${ }^{1}$; mais, era política municipal imitar práticas gregas $^{2}$. Do "modo de vida" grego dá testemunho Estrabão, assinalando, entre outros aspectos, o festival que se realizava de quatro em quatro anos, incluindo competições poéticas (5.4.7), e que rivalizava com os mais famosos de entre os gregos. $\mathrm{Na}$ verdade, os Jogos Napolitanos, apoiados pelo imperador, viriam a ser um modelo para festivais a fundar em Roma ${ }^{3}$ É simbólico do "estatuto" da cidade um episódio imortalizado por Tácito e que coloca Nápoles na biografia

\footnotetext{
${ }^{1}$ Hardie 1983 2, Lomas 2003 1031-1032 com bibliografia.

${ }^{2}$ Ver exemplos de tais práticas em Hardie 1983 3-4.

${ }^{3}$ Hardie 1983 3-4.
} 
de Nero. Considerando o seu talento demasiado grande para performances domésticas, o imperador terá decidido estrear-se precisamente no teatro de Nápoles, "quasi Graecam urbem" (Anais 15.33.2).

$\mathrm{Na}$ vanguarda da cultura grega, a cidade constituía local de erudição e lazer de gregos e romanos, que a alimentavam financeiramente. Nápoles era, para as classes romanas mais altas, uma estância balnear, o local onde os endinheirados tinham as suas uillae e onde procuravam a companhia de intelectuais gregos assistiam aos seus espectáculos, adoptavam o traje grego e participavam nos seus jantares ${ }^{4}$. Além disso, jovens de famílias com poder económico do sul da Itália vinham receber instrução em poesia grega a Nápoles, onde também o pai do poeta ensinou antes da mudança para Roma ${ }^{5}$. A cidade foi, consequentemente, um ponto decisivo de intercâmbio cultural. Referindo-se ao principado de Nero, nota Hardie que Nápoles desafia distinções entre grego e romano nos domínios da poesia e da retórica ${ }^{6}$.

É nesta cidade que Estácio cresce e se forma, filho de um grego dedicado à escrita e ao ensino de poesia na sua língua. É possível que o pai do poeta frequentasse a corte de Nero. Hardie coloca a hipótese de que a mudança da família para Roma se relacione com o imperador. Conhecendo-se as suas aspirações culturais, não seria despropositado que Nero tivesse apoiado uma figura napolitana que se salientava na literatura ${ }^{7}$. De resto, a propriedade de Estácio, a que este se refere para agradecer o fornecimento de água que Domiciano lhe facultou, pode ter sido uma oferta imperial ao pai do poeta ${ }^{8}$.

Nas Silvas, Nápoles é Parténope, a sereia que, guiada por Apolo com o auxílio de uma pomba, terá fundado a cidade 9 . Em todos os livros das Silvas se faz o encómio de Nápoles, seja devido às suas qualidades, seja pela grandiosidade das figuras do círculo de Estácio que a ela estão associadas. No livro 1, no epitalâmio em honra de Estela e Violentila, Estácio partilha com a noiva a origem napolitana; ambos nasceram, pois, no regaço de Parténope (1.2.260-2). Já no livro seguinte, a cidade faz parte da deleitosa paisagem de uma das janelas da uilla surrentina de Pólio Félix (2.2.84), o principal patrono de Estácio em Nápoles, e a quem o poeta dedica o livro 3. Isto torna-o o livro mais "napolitano" das Silvas. Logo no primeiro poema, é o deus Hércules, honrado por Pólio com um novo templo, quem refere Nápoles entre os locais

${ }^{4}$ Hardie 1983 2-4.

${ }^{5}$ Sobre o tema ver Hardie 1983 9-10, Nauta 2002200 e McNelis 200269 com bibliografia.

${ }^{6}$ Hardie 1983 3-4.

${ }^{7}$ Hardie 1983 2, 12. Estácio tece comentários sobre a sua vida privada em Silvas 3.5, 5.3.

${ }^{8}$ Hardie 1983 12-14. Sobre a hipótese de Domiciano ter sido aluno do pai de Estácio ver pp. 11-12.

9 Silvas 3.5.78-80, 4.4.52-4, 4.8.45-9. Apolo desempenha frequentemente o papel de divindade patrona da colonização (é esse o caso em Eneida 3.161-2, Tebaida 7.664). Laguna 1992380. 
associados à juventude do patrono de Estácio (3.1.93). Não é de estranhar, pois, que Parténope observe com agrado os jogos atléticos que celebram a dedicação do templo (3.1.151-2) ${ }^{10}$. O mais rasgado elogio da cidade ocorre em Silvas 3.5. Estácio procura persuadir a esposa, Cláudia, a mudar-se consigo para Nápoles. Depois de celebrar a fidelidade da companheira, o poeta elogia a Campânia, para se centrar por fim na sua cidade natal (74-104). O encómio de Nápoles constitui, assim, um argumento no âmbito de uma suasoria. A cidade é elogiada pelo seu meio natural e cultural. Os atractivos de Nápoles são complementados pelos das cidades vizinhas: Baias, Cumas, Miseno, Gauro, Cápreas, Surrento, Pitecusas, Estábias ${ }^{11}$. No livro 4, além de recordar novamente o mito de fundação da cidade (4.4.52-54), Estácio imagina Parténope rejubilando com o nascimento de mais um filho de Júlio Menécrates, genro de Pólio (4.8.1). A cidade deve ainda assumir o papel de protectora do túmulo do pai de Estácio, a quem o poeta dedica um epicédio no último livro (5.3.104-115) ${ }^{12}$. De acordo com Silvas 3.5, o poeta terá planeado regressar para Nápoles após o final do livro 3, publicado no ano 94; mas não é certo que o plano se tenha concretizado ${ }^{13}$.

\section{Roma eloquente}

As Silvas, como poemas que celebram ocasiões, possuem um cariz panegírico que choca a sensibilidade de muitos leitores modernos, em particular quando o elogiado é um imperador que as fontes retratam como uma figura temível e terrível. É-lhe dedicado o primeiro poema das Silvas, que se centra na sua gigantesca estátua equestre. Outro poema celebrará as Saturnais, nas calendas de Dezembro (1.6); e o panegírico toma a forma de uma composição cantando o cabelo do "favorito" de Domiciano, Eárino, em Silvas 3.4. Abre o livro 4 um ciclo dedicado ao imperador: o primeiro poema celebra a tomada do consulado pela décima sétima vez; o seguinte centra-se na Domus Flauia, onde Estácio havia sido convidado a participar num banquete que contava com a presença do imperador; por último, 4.3 enaltece uma obra pública de grande interesse e visibilidade, a Via Domiciana, que liga Sinuessa a Putéolos, facilitando a ligação entre Roma e a região da Campânia.

Independentemente da veracidade dos relatos que fazem de Domiciano uma figura hedionda ${ }^{14}$, e não sendo este o local para discutir a "adesão" de

${ }^{10}$ Este passo coloca um problema textual, exposto em Laguna 1992180.

${ }^{11}$ Sobre Silvas 3.5 ver Laguna 1992 338-392, Nauta 2002 316. Uma perspectiva diferente apresenta Newlands, de acordo com a sua leitura das Silvas como poemas que manifestam ansiedade em relação ao regime de Domiciano (ver Newlands 2002 195-197).

${ }^{12}$ Hardie 1983 67-68 sobre o elogio de Nápoles e de figuras napolitanas.

${ }^{13}$ Ver Nauta 2002204.

${ }^{14}$ Sobre este problema ver Wiseman 1996. 
Estácio ao programa imperial, importa ler o encómio do imperador no seu contexto e apreciar a originalidade que apresenta nas Silvas. Lembrando a proposta feita no início deste trabalho, centrar-me-ei num dos traços mais interessantes dos poemas que homenageiam Domiciano: o facto de o elogio ser proferido, por vezes, por figuras mitológicas que animam locais simbólicos da cidade. Refiro-me concretamente a Cúrcio, que intervém no elogio da estátua equestre de Domiciano em Silvas 1.1, e ao deus Jano, que acolhe e saúda pessoalmente o novo cônsul em Silvas 4.1.

Se é verdade que os oradores mitológicos são recorrentes na épica, uma outra tradição explica melhor o fenómeno nas Silvas. Com efeito, a personificação ou antropomorfização do discurso constituem elementos importantes na poesia panegírica helenística ${ }^{15}$. Coleman apresenta três exemplos de figuras mitológicas que se apropriam do discurso encomiástico ${ }^{16}$ : a eloquente madeixa de cabelo de Berenice, uma das mais famosas criações de Calímaco (fr. 110 Pf.), votada pela rainha pelo regresso do marido, Ptolemeu III, da guerra na Síria; o discurso de Apolo, ainda por nascer, no hino a Delos (4.162-6), impedindo a mãe de o dar à luz na ilha de Cós, destinada a ser o berço de outro "deus", Ptolemeu II; e a ilha de Cós, com o recémnascido faraó nos seus braços, no idílio 17 de Teócrito (64-71), rogando a sua estima e exortando-o a emular o comportamento honroso de Apolo para com o local onde nasceu. Estes oradores são intervenientes pertinentes, pois estão directamente envolvidos nas situações de que o panegírico nasce. Ora, uma atmosfera semelhante aproxima a Roma imperial da Alexandria dos Ptolemeus. Coloca-se aos poetas, em ambos os casos, o problema da abordagem de um governante único. É possível que os poemas que celebram os faraós e os seus monumentos tenham proporcionado modelos encomiásticos aos poetas augustanos e, mais tarde, a Estácio ${ }^{17}$. No contexto augustano, é difícil não reconhecer pontos de contacto entre a tradição encomiástica a que nos temos vindo a referir e o discurso de Apolo em Propércio 4.6, o aetion do templo dedicado por Octaviano ao deus pelo auxílio prestado na batalha de Áccio. É o próprio Apolo que interpela Octaviano, incitando-o à batalha; e a sua intervenção é seguida pela de um outro deus, Júlio César ${ }^{18}$.

${ }^{15}$ Coleman 1988 63-65.

${ }^{16}$ Coleman 1999 76-77 ressalva que a madeixa de cabelo de Berenice se distingue dos outros dois oradores mencionados por proferir todo o poema, e não apenas uma parte, e por não ser uma figura mitológica convencional.

${ }_{17}$ Coleman 1999 78-79.

${ }^{18}$ Propércio 4.6.37-44, 59-60: "E disse: «Ó salvador da terra, oriundo de Alba Longa,| Augusto, de fama superior aos teus avôs Troianos,| vence agora no mar, pois já é tua a terra: por ti combate este arco, | e todas as flechas que trago aos ombros estão do teu lado.| Liberta do medo a pátria, que confiante agora na tua protecção| acumula as preces do povo sobre o teu navio.| Se não a defendes, é porque Rómulo, ao tomar os auspícios da cidade,| interpretou 
Coleman chamou já a atenção para a necessidade de entender o tom do discurso de Apolo à luz da técnica encomiástica helenística. Propércio é acentuadamente mais subtil do que Estácio, mas inspira-se na mesma estratégia encomiástica ${ }^{19}$.

E se não nos limitarmos ao fenómeno da atribuição de voz a figuras mitológicas, encontraremos ainda mais paralelos relevantes entre as Silvas e a celebração de governantes e/ou ocasiões na poesia helenística. A pertinência desta abordagem fica clara quando se compara, por exemplo, Silvas $1.1 \mathrm{com}$ composições que celebram monumentos helenísticos, como o Colosso de Rodes (AP 6.171) e o farol de Alexandria (Posidipo AB 115) ${ }^{20}$; o poema de Estácio relaciona-se, ainda, com as experiências de Calímaco envolvendo estátuas, nos Aetia e nos Iambos ${ }^{21}$. O estudo das Silvas à luz desta tradição afigura-se, pois, necessário: não apenas ajuda a compreender o projecto poético de Estácio, como torna mais evidente a originalidade e a imaginação do poeta.

A “egiptofilia" dos Flávios, e de Domiciano em particular, é um factor a ter em conta quando se equaciona a relação entre o encómio do imperador e o panegírico helenístico. É sabido que Domiciano construiu um complexo de templos egípcios no campo de Marte, dedicados a Ísis e Serápis; no centro deste complexo figuraria o seu obelisco, no qual se leriam títulos faraónicos aplicados ao imperador ${ }^{22}$. Ora, para o governante que exibe estes gostos, seria certamente lisonjeador ser homenageado, em poesia, nos mesmos moldes que os Ptolemeus.

Um outro factor favorece a hipótese de Estácio se ter inspirado na poesia panegírica do tempo daqueles faraós. Chamou-se já a atenção para o perfil do seu pai: segundo o testemunho de Silvas 5.3, ensinara poesia helenística ${ }^{23}$. Além disso, entre as actividades de um poeta profissional encontrar-se-ia o encómio, em ocasiões públicas ou domésticas. Esta vertente do trabalho do

mal as aves que voavam do Palatino. [....]| Lá do astro idálio, César, seu pai, contempla-o com admiração:| «És um deus: esta vitória prova que és do meu sangue.» Cito a tradução de J. A. Segurado e Campos em Nascimento 2002 237-239.

${ }^{19}$ Coleman 2003.

${ }^{20}$ Ver respectivamente Hardie 1983 131-132 e Obbink 2004.

${ }^{21}$ Ao descrever a estátua, Estácio faz, em alguns momentos, associações simbólicas. Talvez Calímaco proporcione um paralelo para tal gesto. O poeta dialoga com a estátua de Apolo num fragmento dos Aetia (114 Pf.); parece dar uma explicação simbólica do arco que Apolo segura com a mão esquerda; na mão direita, tem as Graças. Ver Hardie 1983 132, Kerkhecker 1999 147-197, 204-207.

${ }^{22}$ Ver Malaise 1972.

${ }^{23} \mathrm{O}$ pai de Estácio ensinaria os poetas épicos e didácticos (Homero, Hesíodo, Epicarmo), cinco dos nove líricos, os alexandrinos Calímaco, Lícofron, Sófron, Corina - ficamos a saber no epicédio que Estácio lhe dedica (Silvas 5.3.148-58), com a intenção de mostrar a sua erudição e consequente versatilidade como poeta. 
pai de Estácio terá certamente influenciado de forma decisiva uma obra do carácter das Silvas ${ }^{24}$.

Havia no forum romano um local sagrado e muito antigo, envolto em mistério, associado a várias lendas e considerado uma porta para o "outro mundo". Trata-se do Lago Cúrcio, que recebe o nome, na versão adoptada por Estácio, do herói republicano Quinto Cúrcio, imortalizado pela sua deuotio em 362 a. C. ${ }^{25}$. Reza a lenda que era necessário sacrificar "a maior força do povo romano" para apaziguar os deuses. Cúrcio entendeu que a expressão se referia ao valor dos guerreiros romanos; montado no seu cavalo, atira-se ao pântano, que se fecha à sua entrada, indicando a aceitação do sacrifício ${ }^{26}$. $\mathrm{O}$ acto de Cúrcio coloca-o na galeria dos heróis republicanos como um exemplo de coragem, de valentia, e símbolo da entrega que salva a pátria ${ }^{27}$. É este guerreiro republicano que, em Silvas 1.1, regressa à superfície atraído pelo barulho da operação que visa instalar a imponente estátua equestre de Domiciano, votada após a vitória sobre os $\mathrm{Germanos}^{28}$, perto da sua secular morada. $\mathrm{O}$ guerreiro eternizado pela bravura treme perante $o$ tamanho e o brilho da estátua - reação adequada a quem vive na escuridão do subsolo, num outro mundo, há tantos séculos, e se confronta repentinamente com um monumento gigantesco. Cúrcio mergulha três vezes a cabeça, aterrado, num pântano que já não existe, e só depois se dirige ao novo vizinho:

Saúdo-te, descendente e progenitor de grandes deuses, divindade de que apenas ao longe tinha ouvido falar! Agora é afortunado o meu pântano,]

agora é venerando, pois foi-me permitido conhecer-te de perto

e o teu imortal esplendor contemplar mesmo aqui ao lado.

Uma única vez fui eu que encontrei a salvação de

Rómulo - já tu as guerras de Júpiter, tu as batalhas do Reno, tu o crime civil, tu a montanha que tarda em aderir aos tratados com um longo conflito vergas. Pois se te tivessem gerado os nossos tempos, terias tentado atirar-te ao fundo lago, não me atrevendo eu, mas Roma teria agarrado os teus freios. ${ }^{29}$

${ }^{24}$ Sobre o tema ver Hardie 1983 15-30, McNelis 2002.

${ }^{25}$ Hardie 1983 131-132.

${ }_{26}$ Trata-se de uma versão muito antiga, provavelmente a etiologia original daquele monumento, talvez grega e remontando pelo menos ao século IV a. C. Varrão, De Lingua Latina 5.148-50, oferece três versões do mito. Ver Ogilvie 1970 75-76, Littlewood 2006 127-128.

${ }^{27}$ Fundamental a análise de Coleman 1999 67-70.

${ }^{28}$ A composição de Estácio inspirar-se-á na cerimónia de dedicação da estátua (como o poeta insinua no prefácio ao livro 1), que poderá ter sido conduzida pelo próprio Domiciano, na qualidade de Pontífice Máximo. Estácio parece sugerir o papel duplo de Domiciano como dedicatário e líder da cerimónia religiosa (Hardie 1983 131).

${ }^{29}$ Silv. 1.1.74-83 Courtney: 'Salve, magnorum proles genitorque deorum,| auditum longe 
Silvas 1.1 é um poema longo e complexo ${ }^{30}$ e mereceu interpretações muito diversas $^{31}$. Focaremos apenas alguns aspectos do protagonismo de Cúrcio e a dimensão simbólica da sua epifania e do seu discurso. Cúrcio é uma voz pertinente para proferir o panegírico por vários motivos. O seu estatuto heróico e sagrado proporcionam elementos de apoio ao encómio. O carácter divino de Domiciano é um dado adquirido nas Silvas; por isso, não surpreende que a presença da estátua imperial nobilite o lacus, em vez de ser o lacus a nobilitar o novo monumento. O herói habita a vizinhança da estátua. Acordá-lo e trazê-lo à superfície são maneiras de salientar que aquela causa um enorme impacte no coração da cidade. A orientação da estátua é muito significativa. $\mathrm{O}$ cavaleiro olha na direcção do templo de Júlio César, o que oferece ao poeta um pretexto para comparar Domiciano àquele governante (o imperador supera-o em clemência e teria evitado as guerras civis); está ladeado pelas Basílicas Júlia e Emília e protegem-lhe as costas os templos de Tito e Vespasiano e o templo da Concórdia.

O imperador integra um novo elemento, a estátua, na mais simbólica zona de Roma, tomando posição entre os antigos vultos da cidade, enfrentando-os e superando-os; são disso exemplo César e Cúrcio. O guerreiro assinala a distância que o separava do imperador, contrastando-a com a actual proximidade. Esta ultrapassa a dimensão física, topográfica, sugerindo uma analogia entre um

numen mihi. nunc mea felix,| nunc veneranda palus, cum te prope nosse tuumque| immortale iubar vicina sede tueri| concessum. semel auctor ego inventorque salutis| Romuleae: tu bella Iovis, tu proelia Rheni,| tu civile nefas, tu tardum in foedera montem| longo Marte domas. quod si te nostra tulissent | saecula, temptasses me non audente profundo| ire lacu, sed Roma tuas tenuisset habenas.'

${ }^{30}$ Depois de exprimir o espanto que a gigantesca estátua suscita, alvitrando que poderia ser obra de um deus (1-7), Estácio compara-a favoravelmente ao cavalo de Tróia (8-21) e centra-se no local que ela ocupará, digno da sua grandiosidade (22-31). A descrição da estátua começa pelo cavaleiro, mais alto que os templos, travando guerras com a mão direita e exibindo na esquerda uma estatueta de Minerva (32-45); foca então o cavalo, comparado a alguns dos mais notáveis das artes e mitologia (46-55), para terminar no impacte da sua presença e força que empresta às mãos daqueles que trabalham em tão grandiosa obra (56-66). Depois da epifania de Cúrcio e do seu discurso, a estátua é dita superar a de Júlio César - em frente ao templo do Divino César - na mesma medida em que o novo governante supera o antigo (84-90). Canta-se, por fim, a eternidade da obra - superior a monumentos como o Colosso de Rodes -, que será visitada pelos membros divinizados da família imperial (91-98) e que é apresentada como uma oferenda do senado e do povo ao imperador, a quem se deseja uma vida longa (99-107). Consulte-se Geyssen 1996, monografia exclusivamente dedicada ao poema.

${ }^{31}$ Alguns críticos discernem em Silvas 1.1 um conjunto de críticas veladas a Domiciano, numa corrente interpretativa a que aludimos na nota 11. É o caso de Ahl 1984a e Ahl 1984b. Não é esta a minha leitura; apresenta igualmente reservas em relação àquela perspectiva L. Morgan, BMCR 2002.09.13. Ver ainda E. Spentzou (2004), JRS 94 257-8; S. Myers (2004/5), CJ 100 213-215; W. J. Dominik (2006), CR 56 359-360. 
“salvador" de Roma e o outro ${ }^{32}$. Mas Domiciano supera sempre Cúrcio: o herói republicano é ofuscado pelo herói que ao seu lado se instala. Cúrcio salvou Roma apenas uma vez, Domiciano fê-lo repetidamente - um pretexto para Estácio elencar as vitórias do imperador. Até em coragem o novo vizinho teria ultrapassado Cúrcio. Roma tê-lo-ia impedido de atirar-se ao pântano no seu lugar porque a cidade precisa que o imperador viva.

Mas a propriedade deste orador justifica-se ainda de outra maneira. $\mathrm{O}$ poeta refere que é o próprio Cúrcio quem guarda o local. Hardie chama a atenção para a hipótese de que, quando se erigisse um objecto numa terra do interesse de outra divindade, essa mesma divindade local fosse interpelada. É o caso do epigrama de Posidipo sobre o grande farol de Faros: a composição é dirigida a Proteu, o patrono do local, mas o farol é dedicado aos "deuses salvadores" e a Zeus Sóter, epítetos que dificilmente não pretenderiam incluir os Ptolemeus ${ }^{33}$. Ora, o discurso de Cúrcio pode, pois, substituir a interpelação ao protector do local, invertendo a tradição - o interpelado, que seria Cúrcio, guardião secular daquele sítio, desempenha em Silvas 1.1 o papel daquele que interpela; e a divindade a quem o poema é dirigido, o dedicatário da oferenda, é o próprio imperador.

A dignidade e a credibilidade desta voz mítica tornam o cumprimento a Domiciano elegante ${ }^{34}$. O estatuto lendário de Cúrcio permite que o poeta crie um discurso grandioso, dando-lhe formalidade, solenidade - um registo adequado ao encómio de um imperador e de um deus ${ }^{35}$.

Estácio volta a inverter as expectativas em Silvas 4.1, que assinala o décimo sétimo consulado de Domiciano, no ano 95. No início de um novo livro, de um novo ano e de um novo consulado, o poema é dominado pela saudação que o próprio deus dos inícios, Jano, dirige ao imperador ${ }^{36}$. Trata-se de uma gratiarum actio, um agradecimento a Domiciano por ter aceitado a honra de ser novamente cônsul ${ }^{37}$; o consulado é apresentado, pois, como uma cedência do imperador à pressão do senado. As leis, as magistraturas e toda a Roma se alegram, e até as estrelas; mas Domiciano brilha mais do que elas. Os motivos do júbilo universal e do consulado como cedência são reiterados por Jano, que se coloca a par do imperador no papel de renovador dos anos e insiste na ausência de paralelo, na história de Roma, para o desempenho de Domiciano como governante:

\footnotetext{
${ }^{32}$ É questão colocada por Coleman 199969.

${ }^{33}$ Hardie 1983 131-132.

${ }^{34}$ Como nota Coleman 199970 a propósito de Cúrcio.

${ }^{35}$ Coleman 199969.

${ }^{36} \mathrm{Um}$ estudo das fontes do discurso passa necessariamente pelos Fastos. Jano é o orador no primeiro dia (Fast.1.101-44).

${ }^{37}$ Hardie 1983193.
} 
Saúdo-te, grande progenitor do mundo, que comigo procuras renovar os séculos! Nessa qualidade deseja ver-te sempre no meu mês a tua Roma. Assim devem nascer os tempos, assim começar os anos. Oferece aos fastos sem parar motivos de júbilo! Esses ombros, que os envolva a pretexta com abundante púrpura tecida pelas mãos da tua Minerva. Vês como existe um brilho diferente nos templos, um fogo mais alto nos altares, e as próprias estrelas do meu inverno cintilam para ti, iguais às tuas virtudes? Exultam os cavaleiros e os povos, e os senadores vestidos de púrpura, e toda a magistratura toma do cônsul a sua luz. Que ano anterior, pergunto-te, teve algo parecido? Vamos, diz, poderosa Roma, e comigo, longa Antiguidade, enumera os fastos e não tragas a lume os exemplos menores, mas apenas aqueles que o meu César se digne superar.

Três e mais dez vezes, no decorrer dos anos,

Augusto transportou os lácios fasces, mas tarde começou a merecê-lo:

tu, ainda jovem, ultrapassaste os teus avós. E a quanto renuncias, quanto não permites! Hás-de ser persuadido, todavia, pelas preces do senado, e hás-de consentir muitas vezes este dia. Está por vir uma série

mais extensa, e dar-te-á outras tantas a próspera Roma o ofício curul, e três e quatro vezes mais. Comigo nova idade hás-de fundar, e por ti será novamente inaugurado o altar do antigo Tarento. Hás-de carregar mil troféus - consente, apenas, os triunfos. Falta à Báctria, falta à Babilónia com novos tributos pôr o freio; ainda não está no regaço de Júpiter o loureiro índico, ainda não apresentam petições os árabes e os chineses, ainda não foi honrado todo o ano - dez meses desejam ainda nomes tomados de ti.

(Silv. 4.1.17-43) 38

38 Silv. 4.1.17-43 Coleman: 'Salve, magne parens mundi, qui saecula mecum| instaurare paras, talem te cernere semper| mense meo tua Roma cupit; sic tempora nasci,| sic annos intrare decet. da gaudia fastis| continua; hos umeros multo sinus ambiat ostro| et properata tuae manibus praetexta Minervae.| aspicis ut templis alius nitor, altior aris| ignis, et ipsa meae tepeant tibi sidera brumae| moribus aequa tuis? gaudent turmaeque tribusque| purpureique patres, lucemque a consule ducit| omnis honos. quid tale precor prior annus habebat?| dic age, Roma potens, et mecum, longa Vetustas,| dinumera fastos, nec parva exempla recense| sed quae sola meus dignetur vincere Caesar.| ter Latios deciesque tulit labentibus annis| Augustus fasces, sed coepit sero mereri:| tu iuvenis praegressus avos. et quanta recusas,| quanta vetas! flectere tamen precibusque senatus| permittes hunc saepe diem. manet insuper ordo| longior, et totidem felix tibi Roma curules| terque quaterque dabit. mecum altera saecula condes,| et tibi longaevi renovabitur ara Tarenti.| mille tropaea feres - tantum permitte triumphos.| restat Bactra novis, restat Babylona tributis| frenari; nondum in gremio Iovis Indica laurus, | nondum Arabes Seresque rogant, nondum omnis honorem| annus habet, cupiuntque decem tua nomina menses.' 
Tradicionalmente, o cônsul fala em nome da República; por analogia, o Jano de Estácio fala por Roma, referindo-se à cidade no início das três secções do seu discurso: o comentário da situação presente (17-27), o passado e os seus precedentes (27-33), o futuro (33-42) $)^{39}$. Roma é pertença de Domiciano, omnipotente e próspera.

A atribuição de voz a Jano e a extensão do seu discurso, que ocupa boa parte do poema, são aspectos muito significativos. É costume que o cônsul que entra em funções faça o discurso de gratiarum actio ao imperador pelo beneficium do cargo; mas podia também dar-se o caso de o novo cônsul interpelar directa e pessoalmente $\mathrm{Jano}^{40}$. Estácio explora imaginativamente esta possibilidade. $\mathrm{O}$ poeta inverte os discursos: em vez de o novo cônsul interpelar Jano, é o deus quem interpela o cônsul. Esta é igualmente uma maneira elegante de contornar uma situação melindrosa, o facto de ser o imperador a assumir o consulado.

A legitimidade de Jano para interpelar Domiciano pode conhecer outros fundamentos. Jano estava associado a Aion, a deificação do conceito de eternidade. Ora, testemunhos poéticos e algumas moedas sugerem a hipótese de que Domiciano fosse assimilado às funções de Jano-Aion, representando a eternidade de Roma e do império ${ }^{41}$.

Há ainda mais um aspecto a considerar na relação entre Jano e o imperador. Existia um templo dedicado a Jano no final do Argileto, formando um corredor entre o forum romano e o de César, no local onde Domiciano mandou erguer a nova Cúria em 94. O deus apresentaria duas faces, justificando o nome Geminus, e o templo teria duas entradas. Por ocasião das obras da Cúria, o imperador ofereceu ao deus um novo templo, no qual Jano figuraria com uma outra morfologia, com quatro faces, o que explica a sua designação, Jano Quadrifronte. Domiciano instalou-o no forum por si idealizado, entre o de Augusto e o Templo da Paz. O forum era conhecido como "transitorium" por constituir o principal caminho entre a Subura, o forum romano e os outros fora imperiais ${ }^{42}$, e exibiria detalhes arquitectónicos semelhantes aos do palácio imperial. Num extremo do forum erguia-se o templo em honra da deusa preferida de Domiciano, Minerva, e no centro ou no extremo oposto encontrar-se-ia o templo de Jano Quadrifronte. Cada face do deus contemplaria, simbolicamente, um forum: o de César, o de Augusto, o forum romano e novo forum de Domiciano. É ainda de assinalar que esta localização o tornava vizinho do Templo da Paz, a que Jano se encontra proverbialmente associado. Marcial celebra este monumento no livro 10:

\footnotetext{
${ }^{39}$ Hardie 1983193.

${ }^{40}$ Ver Silv. 4.2 e Mart. 8.8. Com Hardie 1983 193, nota 71.

${ }^{41}$ Hardie 1983193.

${ }^{42}$ Platner - Ashby 1929 278-280.
} 
Pai magnífico dos anos e do luminoso universo,

o primeiro que invocam as preces e os votos públicos,

antes habitavas uma morada exígua, ponto de passagem

por onde Roma em peso trilhava o seu caminho.

Agora teus limiares enchem-se das dádivas de César

e contas tantos foros, Jano, quantas são as caras.

Mas tu, pai venerando, grato por tamanha oferenda, guarda tuas férreas portas fechadas com aldraba sempre posta. ${ }^{43}$

Parece-me relevante que Jano seja, além da divindade associada aos inícios e à tomada da magistratura consular, o deus honrado por Domiciano com um novo templo, numa localização privilegiada - no forum concebido pelo imperador, na vizinhança da sua Minerva, e com o simbolismo de unificar os fora, o coração de Roma. Se a estátua equestre de Silvas 1.1 dominava o perímetro do forum romano e os edifícios circundantes, o novo Jano articula as principais praças da cidade, símbolos de outras fases da história de Roma, marcas de outros governantes. Tal articulação seria particularmente clara se o templo tivesse de facto quatro entradas e ocupasse a extremidade do forum de Domiciano ${ }^{44}$. Permanece em dúvida, no entanto, de onde é que Estácio imagina o deus proferindo o seu discurso em honra do imperador. $\mathrm{O}$ modo como Estácio descreve o deus adequa-se mais à sua figuração como Geminus - possui uma "voz dupla", são referidas duas entradas (Silv. 4.1.12, 16); no entanto, Jano parece encontrar-se perto do Templo da Paz, o que se ajusta à sua nova localização (Silv. 4.1.13). Na proposta de Coleman, as referências não são incompatíveis: Jano dirige-se ao imperador do seu mais antigo templo, aludindo igualmente ao novo ${ }^{45}$.

3. Nos poemas de Calímaco e Teócrito a que nos referimos atrás, a fantasia encontra-se ao serviço do panegírico. $\mathrm{O}$ mesmo pode dizer-se dos poemas das Silvas em que a palavra é dada a uma figura mitológica: o orador concretiza a fusão do mundo real com o mítico, possibilidade posta ao serviço do elogio, emprestando-lhe originalidade, diversificando-o. Com efeito, o "aparecimento" do orador justifica uma breve narrativa introdutória; a sua envergadura mitológica faz dele uma figura com propriedade para discursar, permitindo assim a variação da voz que profere o encómio; o artifício permite, ainda, avançar e recuar no tempo ${ }^{46}$, comparar passado e presente. É prática de

${ }^{43}$ Marcial 10.28. Cito a tradução de Paulo Sérgio Ferreira em Pimentel 2004 34-35.

${ }^{44}$ A localização do templo a Jano Quadrifronte é disputada. Permanece igualmente em aberto a morfologia do templo, tanto o de Jano Geminus como o de Jano Quadrifronte. Ver Anderson 1984137 com bibliografia; Platner-Ashby 1929 280; Coleman 1988 62-65, 69-71.

${ }^{45}$ Coleman 198871.

${ }^{46}$ Coleman 1999 78-79. 
Estácio, à semelhança do que sucede nos poemas gregos referidos, atribuir o discurso a uma divindade que esteja associada ao local ou à ocasião ${ }^{47}$. Cúrcio e Jano constituem, pois, oradores cuidadosamente seleccionados. Ambos se enquadram no cerimonial da ocasião que celebram, Cúrcio fazendo o papel da divindade local, Jano como o deus a quem o discurso do início do ano poderia ser endereçado. Estácio joga com as convenções das cerimónias, adaptando-as às necessidades da poesia; é assim que o destinatário convencional de um discurso toma o lugar, no universo de Estácio, de orador.

Mas Cúrcio e Jano têm ainda outro aspecto em comum: testemunham a apropriação do espaço por parte de Domiciano. O fenómeno repete-se, de resto, no caso da Via Domiciana (Silv. 4.3), celebrada na voz do rio Volturno, drenado e canalizado no decurso da obra, e da Sibila de Cumas, símbolo do final da viagem a sul. Ao dar voz a Cúrcio e Jano, Estácio acaba por chamar a atenção para aspectos da intervenção urbanística do imperador ${ }^{48}$. As duas figuras são símbolos de uma Roma em transformação. Domiciano procura abrir espaço para si entre as marcas deixadas por aqueles a quem outrora pertenceu a cidade.

${ }^{47}$ Coleman 198865.

48 Sobre a intervenção de Domiciano na cidade existe abundante bibliografia, da qual saliento Darwall-Smith 1996. Ver também Dewar 2008 65-72. 